\title{
Prediction of Scatter in Creep Crack Growth Data from Creep Failure Strain Properties
}

\begin{abstract}
Procedures are available for determining the creep crack growth (CCG) properties of materials experimentally in terms of the creep fracture mechanics parameter $C^{*}$. When these properties have not been measured, predictions can be made from models of the cracking process. These models show that creep crack growth rate at a given value of $C^{*}$ is most sensitive to the creep ductility $\varepsilon_{f}^{*}$ appropriate to the state of stress at a crack tip. For plane stress conditions, it is found that $\varepsilon_{f}^{*}$ can be taken to be equal to the uniaxial creep ductility $\varepsilon_{f}$ of a material and for plane strain to be given by $\varepsilon_{f} / 30$. Hence, in this paper, uniaxial creep properties on type $316 \mathrm{~L}(\mathrm{~N})$ austenitic stainless steel and two $9 \% \mathrm{Cr}$ steels, designated P91 and $\mathrm{P} 92$, in the temperature range $500-750^{\circ} \mathrm{C}$ are reported and scatter in the data identified from statistical analysis. For each steel, the dependence of creep ductility on stress and temperature is determined. It has been found that none of the rupture time $\left(t_{R}\right)$, creep strain rate $(\dot{\varepsilon})$, and net section stress $\left(\sigma_{\text {net }}\right)$, parameters has a better relationship with the creep failure strain. Hence, none of these parameters characterizes better than the other the creep ductility's behavior. Additionally, it has been observed that although the creep failure strain of $316 \mathrm{~L}(\mathrm{~N})$ is independent of these parameters, it increases with temperature. In contrast, the creep failure strain of P91 is slightly sensitive to $\sigma_{\text {net }}$ but is overcompensated by the scatter and so can be assumed stress independent. The creep failure strain of P91 is seen to be also insensitive to temperature. For P92, $\varepsilon_{f}$ goes from a lower to an upper shelf through a transition region. Thus the best solution to characterize the failure strain behavior is to use a polynomial solution. Creep crack growth properties obtained on cracked compact tension and $\mathrm{C}$-shaped specimens are also presented. Probabilistic analysis, based on Monte Carlo simulation methods, is employed to predict scatter in the creep crack growth data from scatter in the uniaxial creep properties. In most instances, close agreement is found between the experimentally measured scatter in the cracking results and that predicted from the scatter obtained from creep ductility data.
\end{abstract}

KEYWORDS: uniaxial creep properties, creep ductility, creep crack growth, probabilistic methods

\section{Nomenclature}

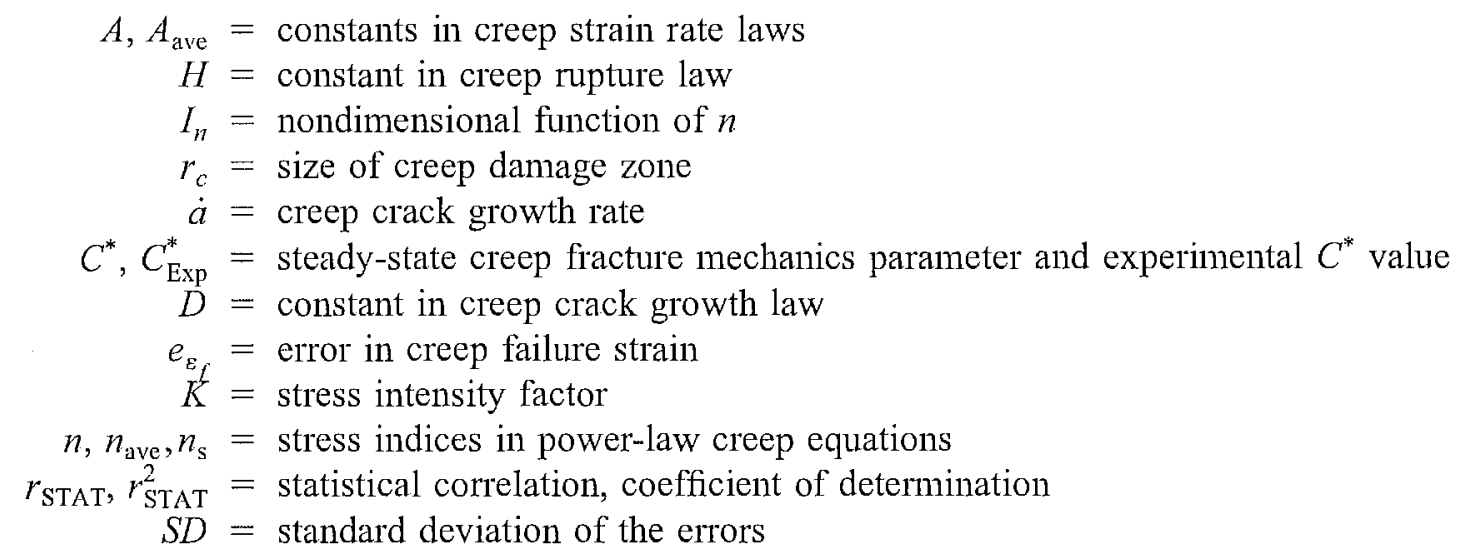

Manuscript received May 7, 2005; accepted for publication September 7, 2005; published December 2005. Presented at ASTM Symposium on Fatigue and Fracture Mechanics: 35th Volume on 18-20 May 2005 in Reno, NV; R. E. Link and K. M. Nikbin, Guest Editors.

${ }^{1}$ Project manager, Swiss Federal Laboratories for Materials Testing and Research (EMPA-Thun), Laboratory for Materials Technology, Feuerwerk-strasse 39, 3602 Thun, Switzerland.

${ }^{2}$ Principal Reseach Fellow and Professor, respectively, Department of Mechanical Engineering, Imperial College, London, SW7 2BX, United Kingdom. 


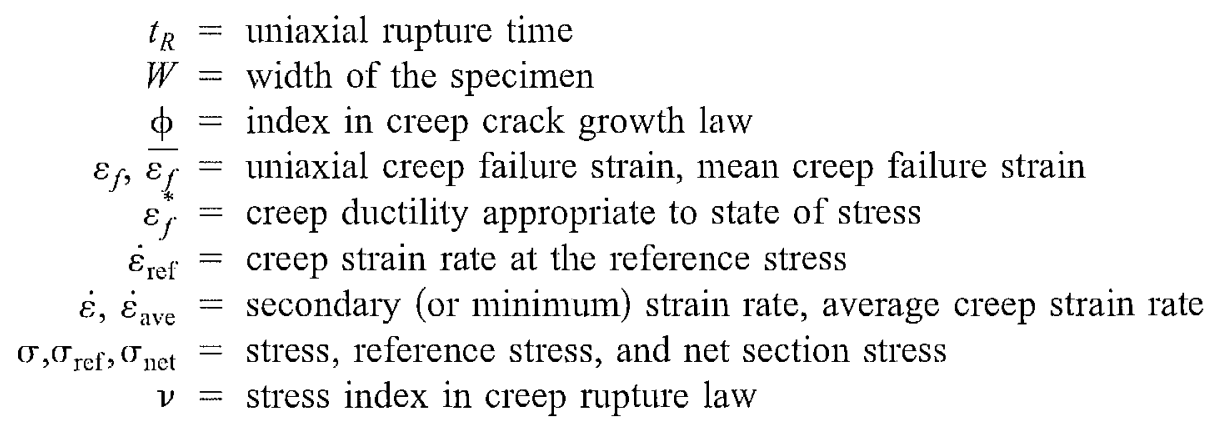

\section{Introduction}

In order to predict the lifetimes of components that operate at high temperatures reliably, it is essential to determine their creep rupture and creep crack growth (CCG) behavior accurately. Several design and assessment procedures are available for dealing with this situation. These include the French A16 [2,3], British Energy R5 [4], and BS 7910 [5] codes. Each of these procedures adopts the same basic principles by describing creep strain rate $\dot{\varepsilon}$ and crack growth rate $\dot{a}$ by the power-law relations

$$
\dot{\varepsilon}=A \cdot \sigma^{n}
$$

and

$$
\dot{a}=D \cdot C^{* \phi}
$$

where $A, n, D$, and $\phi$ are material constants, $\sigma$ is stress, and $C^{*}$ is the creep fracture mechanics parameter [6,7]. In laboratory tests this term is determined experimentally based on the ASTM E 1457 [8] procedure. In components, it is usually estimated from reference stress methods $[9,10]$. A deterministic approach is employed most often to make assessments and decisions have to be made about whether to choose upper or lower bound material properties to achieve conservative predictions. A worst case combination of bounds may result in excessive conservatism.

Although $D$ and $\phi$ are best obtained experimentally fiom tests carried out according to ASTM E 1457 [8], models are available for predicting their values from uniaxial creep data $[11,12]$. For a creep law of the form of Eq 1 these give

$$
\phi=\frac{n}{n+1}
$$

and

$$
D=\frac{(n+1)}{\varepsilon_{f}^{*}}\left[\frac{A \cdot r_{c}}{I_{n}^{n}}\right]^{1 / n+1}
$$

where $r_{c}$ is the size of the creep zone at the crack tip in which damage accumulates, $I_{n}$ is a nondimensional function of $n$ and state of stress, and $\varepsilon_{f}^{*}$ is the creep ductility of the material appropriate to the state of stress at the crack tip. For plane stress conditions $\varepsilon_{f}^{*}$ can be taken as the uniaxial creep ductility $\varepsilon_{f}$ of a material and for plane strain as $\varepsilon_{f} / 30$. Since for most practical purposes $0.7<\phi<1$ and the terms in square brackets in Eq 4 are raised to a small fractional power, Eq 2 can often be simplified to

$$
\dot{a}=\frac{3 \cdot C^{* 0.85}}{\varepsilon_{f}^{*}}
$$

where $\dot{a}$ is in $\mathrm{mm} / \mathrm{h}, C^{*}$ in $\mathrm{MPa} / \mathrm{m}^{2} \cdot \mathrm{h}$ and $\varepsilon_{f}^{*}$ as a fraction.

Replacing $\varepsilon_{f}^{*}$ by either $\varepsilon_{f}$ or $\varepsilon_{f} / 30$ in Eq 5 , it is evident that $D$ in Eqs 2 and 4, and so CCG predictions, are most sensitive to the creep ductility of a material. Consequently, it may be expected that it should be possible to predict the scatter in creep crack growth data from that recorded in the creep ductility data. To enhance the CCG predictions, it is imperative to have a characterization of the failure strain as close as possible to the reality. In this investigation scatter in uniaxial creep strain rate, rupture and creep ductility data are examined to establish the scatter to be expected in cracking properties. Data on austenitic stainless 
steel type $316 \mathrm{~L}(\mathrm{~N})[13,14]$ and two advanced $9 \% \mathrm{Cr}$ steels designated $\mathrm{P} 91$ [15-23] and P92 [19-24] are considered. The results of the characterization will then be used in a probabilistic method in a latter section.

\section{Materials and Experiments}

The data used in this study come mainly from European HIDA, LICON, and CRETE collaborative projects (See Acknowledgment section). Based on these databases, sufficient data were available to allow them to be examined separately as individual batches as well as using them all as one dataset. The nominal chemical compositions of these steels are shown in Table 1. The uniaxial creep data were collected at temperatures in the range 500 to $750^{\circ} \mathrm{C}$ in accordance with ASTM E 139 [25]. The tests were performed on several casts of the steels. The materials were selected on the basis that they are used in the fabrication of some of high temperature power plant components. Emphasis has been placed on the analysis of creep ductility, secondary, and average creep strain rates defined in Eq 6. Large datasets have been analyzed and the statistical results given in this paper in order to be used as benchmark for CCG predictions.

$$
\dot{\varepsilon}_{\mathrm{ave}}=\frac{\varepsilon_{f}}{t_{R}}=A_{\mathrm{ave}} \cdot \sigma^{n_{\mathrm{ave}}}
$$

with rupture life $t_{R}$ expressed as

$$
t_{R}=H \cdot \sigma^{-\nu}
$$

where $A_{\text {ave }}, n_{\text {ave }}, H$, and $v$ are material constants and creep crack growth rate. In these equations when $n=v$, creep failure strain is independent of stress. When $n_{\text {ave }}>v$ creep ductility decreases with decrease in stress.

By combining Eqs 6 and $7, \varepsilon_{f}$ can be expressed in the form of

$$
\varepsilon_{f}=A_{\text {ave }} \cdot H \cdot \sigma^{\eta_{\text {ave }}-\mathrm{v}}
$$

Equation 8 does not predict $\varepsilon_{f}$ of each data point but only its means value as well as the sensitivity of the failure strain according to the applied stress. When $n_{\mathrm{avc}}=\nu, \varepsilon_{f}$ is constant and is equivalent to the mean creep failure strain $\overline{\varepsilon_{f}}$, whereas when $n_{\text {ave }}>\nu, \varepsilon_{f}$ increases as $\sigma$ increases. Therefore, two types of creep failure strain behavior are expected and have been reported by R5 [4]. These are (i) a trend of increasing ductility with increasing net section stress from a lower shelf to an upper shelf and (ii) no clear trend of increasing ductility with stress.

The recommendations of ASTM E 1457 [8] were followed for performing the crack growth tests and in interpreting the results. The results of CCG tests of two types of geometries are presented here which are the compact tension (CT) and c-shape (C). Statistical analysis routines were employed for determining the scatter in the data.

\section{Uniaxial Results}

Results of statistical analyses that have been performed on the entire uniaxial creep data are presented in Tables 2-5 for the $316 \mathrm{~L}(\mathrm{~N})$, P91, and P92 steels, respectively. These tables include information on a wide range of tests on several batches of material. In Table 6 additional results are provided for batches of material on which CCG studies were performed. These tables contain mean values of $n, n_{\text {ave }}, \nu, \overline{\varepsilon_{f}}$, and standard deviation in ductility $S D \varepsilon_{f}$ at each temperature for all the batches of material combined. Also included in Table 6 are the mean values of $D$ and $\phi$ obtained from the cracking data in addition to the standard deviation in crack growth rate.

The dependence of creep ductility on secondary creep rate and stress for three batches of $316 \mathrm{~L}(\mathrm{~N})$ steel at $650^{\circ} \mathrm{C}$, from which CCG tests were performed, are shown in Fig. 1. First, it has been found that none of the following parameters, the rupture time $\left(t_{R}\right)$, the creep strain rate $(\dot{\varepsilon})$, and the net section stress $\left(\sigma_{\text {net }}\right)$, has a better relationship with $\varepsilon_{f}$. Hence, none of these parameters characterizes better than the other the creep ductility's behavior and evidence of this is illustrated in Fig. 1 and Table 2 with the statistical correlation value $r_{\mathrm{STAT}}$. Second, it is difficult to establish a clear trend between different casts. This behavior was expected since it has been observed from Table 2 , that $n_{\text {ave }} \approx n_{s} \approx v$ for $316 \mathrm{~L}(\mathrm{~N})-\mathrm{PM}$. Since 
$\varepsilon_{f}$ is not stress dependent and that no cast influence is perceived (see Fig. 1), it is possible to analyze all creep failure ductility results regardless their cast and origin. This is supported further in Fig. 2 where the creep failure strain is plotted on a normal probability diagram for all the $316 \mathrm{~L}(\mathrm{~N})$ tests at $650^{\circ} \mathrm{C}$. The visual examination of this figure demonstrates that, except for a few points, the data are normally distributed and this is corroborated by a $r_{\mathrm{STAT}}=0.98$. This proves that creep failure strain data can be assumed to be insensitive to the stress and normally distributed. The dependence of creep ductility on stress for the entire dataset is presented in Fig. 3 together with the upper and lower two standard deviation (2SD) bounds. It is apparent, within the range of scatter observed, that creep failure strain can be regarded as independent of stress for this temperature. Similar trends were observed for the other temperatures examined. The mean, standard deviations, and correlation coefficients obtained for each temperature are listed in Table 2. This table and Fig. 4 indicate that the mean creep ductility and the standard deviations for each temperature for $316 \mathrm{~L}(\mathrm{~N})$ stainless steel increase with temperature. The \pm 2 standard deviation $( \pm 2 S D)$ bounds for the average creep strain rate at $650^{\circ} \mathrm{C}$ are shown in Fig. 5 as a function of net section stress. These approximate to a range of about times 22.

The creep failure strain behavior of the two $9 \% \mathrm{Cr}$ steels are different as those obtained on the 316 $\mathrm{L}(\mathrm{N})$ stainless steel as indicated in Tables 3 and 4. Illustrations of the scatter obtained in creep ductilities are shown in Figs 6-9 for the P91 steel. Based on Fig. 6, the P91 creep ductility seems to increase with the net section stress. This is consistent with $\mathrm{Eq} 8$ in conjunction with the results given in Table 3 where $n_{\text {Ave }}>v$. However, this trend disappears when all individual batches of material are combined into one
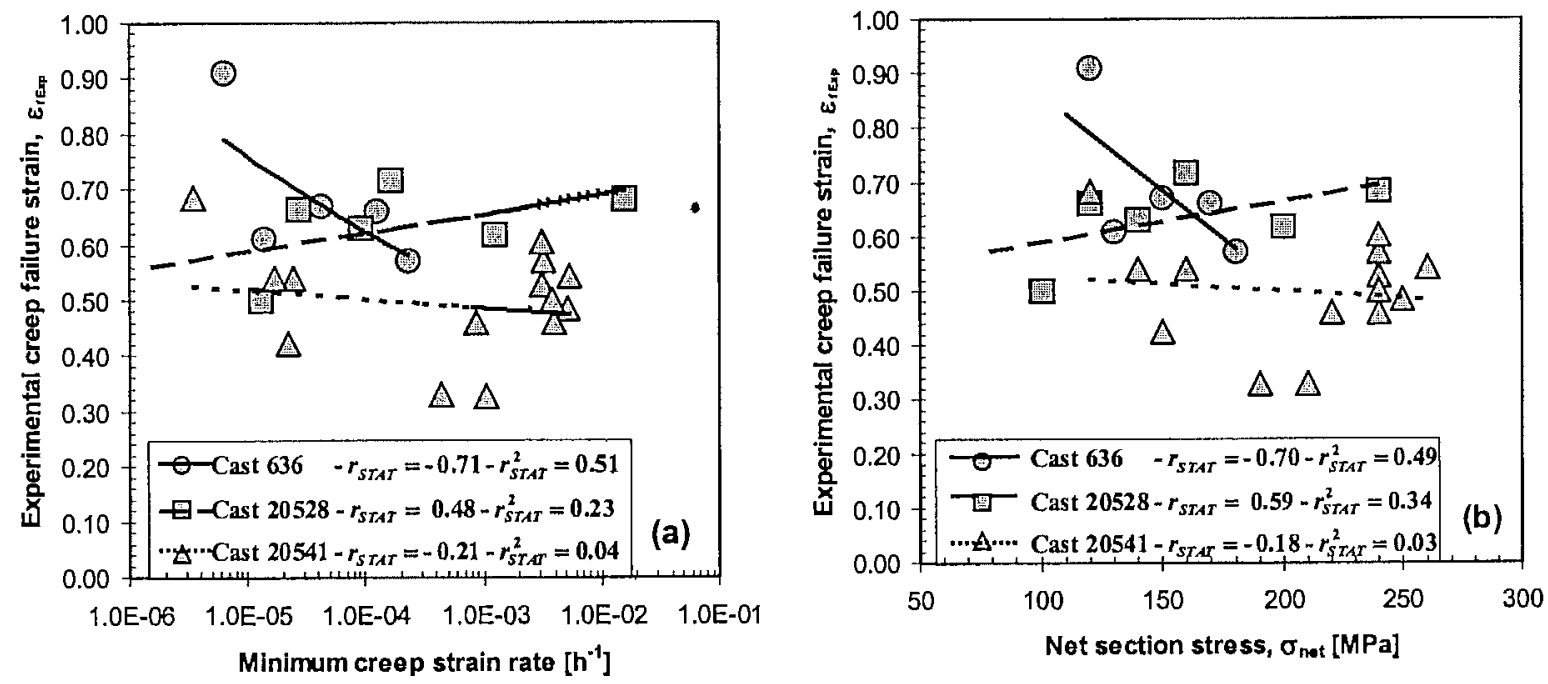

FIG. 1-The effect of (a) secondary creep rate and (b) stress on the creep failure strain for three casts of $316 \mathrm{~L}(\mathrm{~N})$ steel at $650^{\circ} \mathrm{C}$.

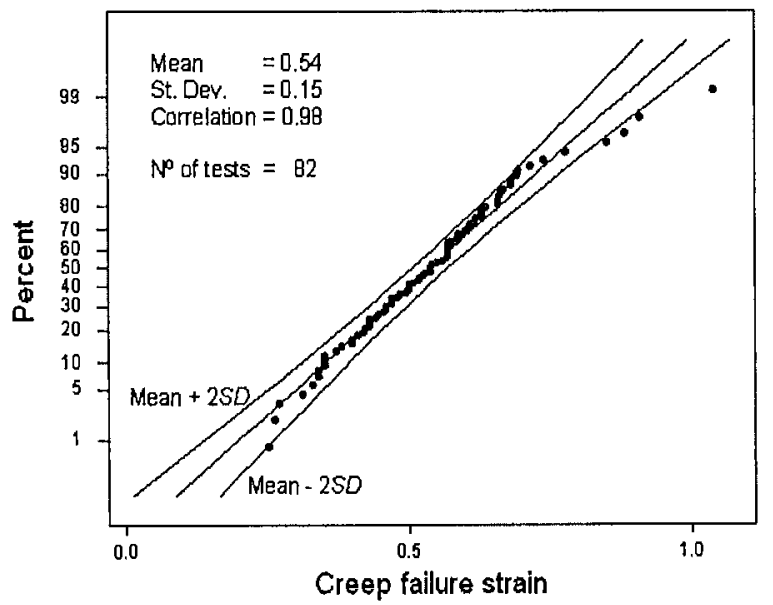

FIG. 2-Normal probability plot of creep failure strain for all tests on $316 \mathrm{~L}(\mathrm{~N})$ steel at $650^{\circ} \mathrm{C}$. 


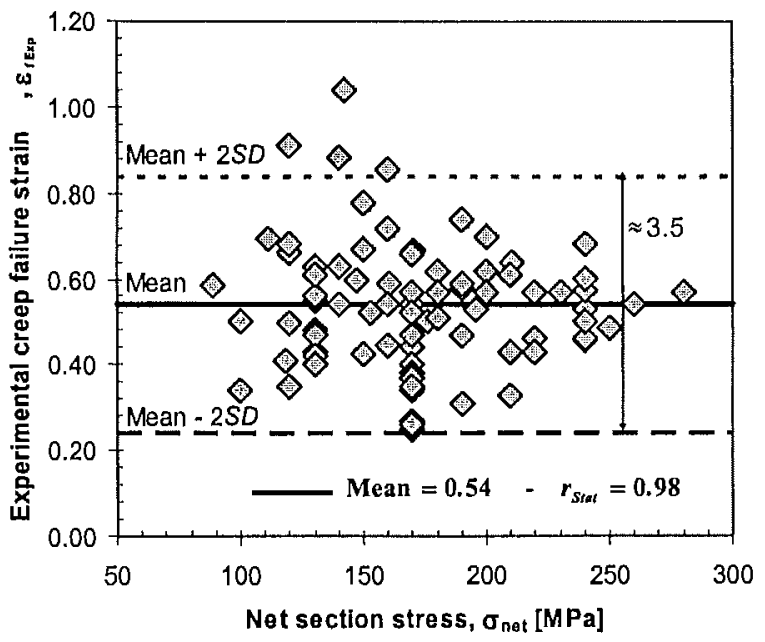

FIG. 3-Creep failure strain as a function of stress for all tests on $316 \mathrm{~L}(\mathrm{~N})$ steel at at $650^{\circ} \mathrm{C}$.

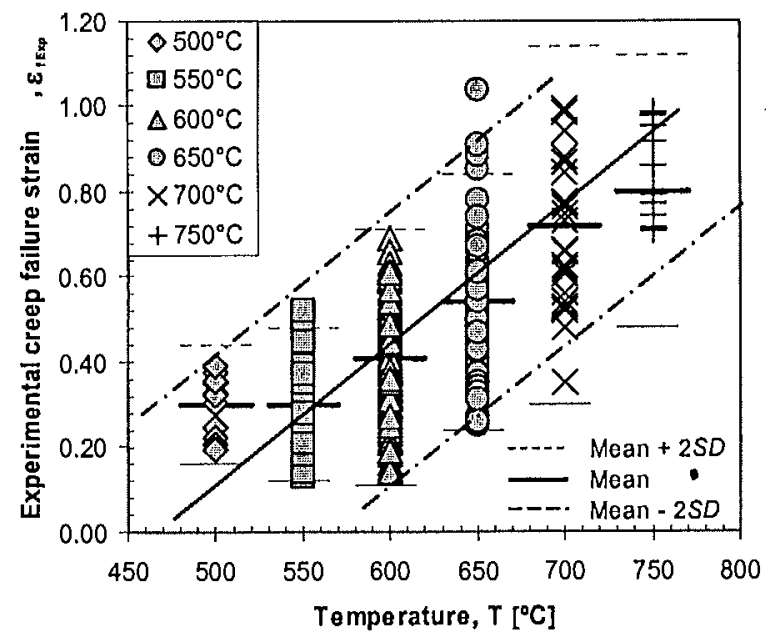

FIG. 4-Effect of temperature on the creep failure strain for all tests on $316 L(N)$ steel.

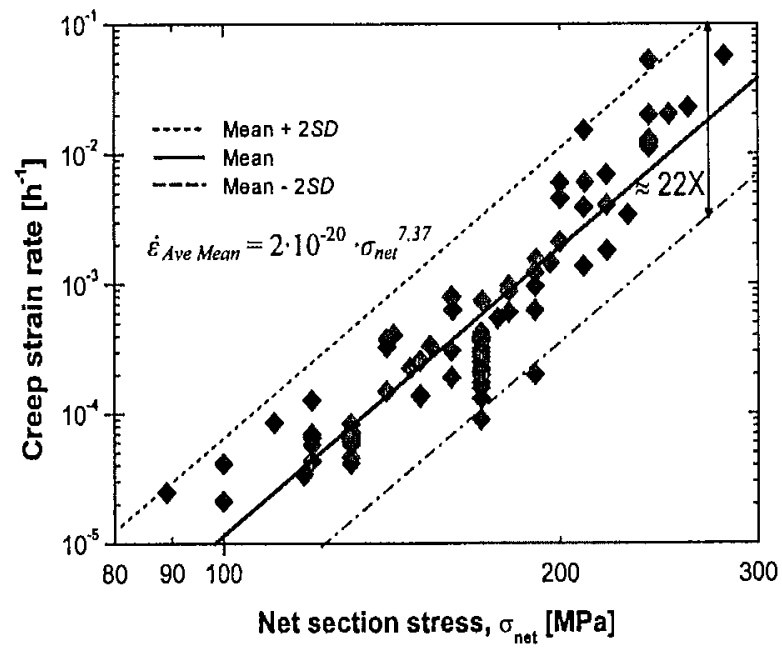

FIG. 5-Average creep strain rate for all tests on $316 \mathrm{~L}(\mathrm{~N})$ steel at $650^{\circ} \mathrm{C}$. 
dataset as evidence from Figs. 7-9. Based on these figures, it is evident that, for the P91 steel, $\varepsilon_{f}$ can be regarded as independent of stress, and so normally distributed. This is demonstrated by making this assumption and testing with the normal probability plot as in Fig. 7. Figure 8 illustrated the results of the complete dataset available for P91 including the mean and \pm 2 standard deviations. Furthermore, P91 is, in contrast to $316 \mathrm{~L}(\mathrm{~N})$, insensitive to temperature, and evidence of this is in Fig. 9. Also dissimilar to 316 $\mathrm{L}(\mathrm{N})$ stainless steel, its scatter for the total dataset rises with an increase in temperature only between 500 and $550^{\circ} \mathrm{C}$. This may be due to the small number of tests available at $500^{\circ} \mathrm{C}$.

The scatter in $\varepsilon_{f}$ for P92 is presented in Figs 10-12. These figures show that $\varepsilon_{f}$ increases with both stress and temperature. The stress dependence can be interpreted in terms of a lower and upper shelf ductility, with a transition region, as reported in R5 - British Energy [4] and seen in Fig. 10, or by a polynomial expression as indicated in Figs 11 and 12. The fitting coefficients to a fifth degree polynomial fit are listed in Table 5. The purpose of the table is to be used as benchmark when no P92 uniaxial data are available for CCG predictions. Even if $r_{\mathrm{STAT}}^{2}$, the coefficient of determination, in Table 5 are not high, the polynomial expression is by far the simplest method to represent the creep ductility behavior since determining the lower and upper shelves linked by the transition only on a statistical basis is not viable. In all cases, it has been found that results on individual batches of material can be combined into one dataset for statistical analysis.

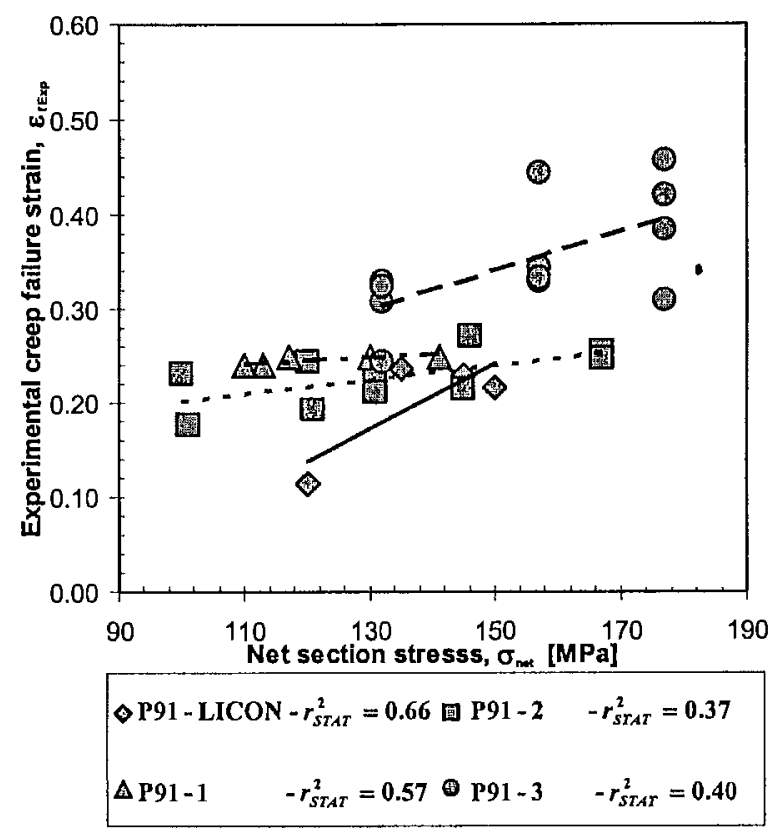

FIG. 6- The effect of net section stress on the creep failure strain for of $P 91$ steel at $600^{\circ} \mathrm{C}$.

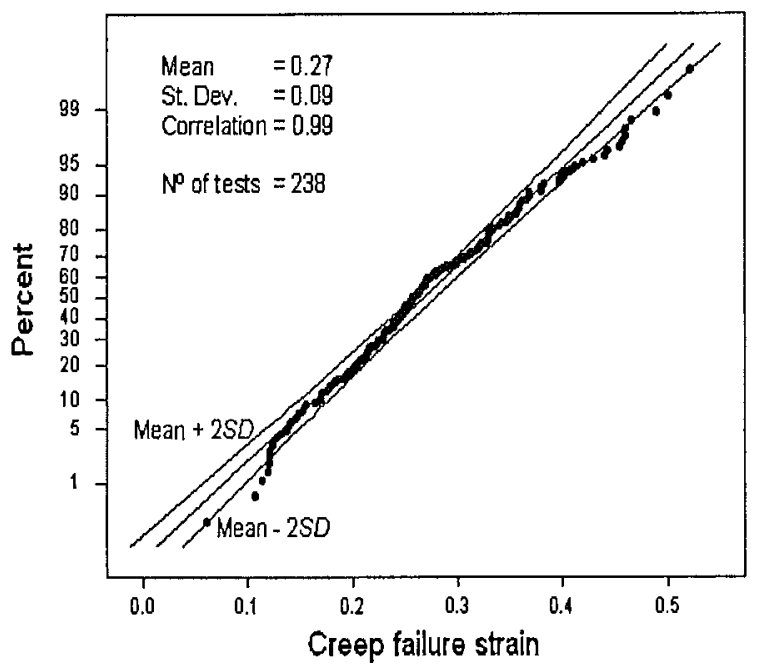

FIG. 7-Normal probability plot of creep failure strain for all tests on P91 steel at $600^{\circ} \mathrm{C}$. 


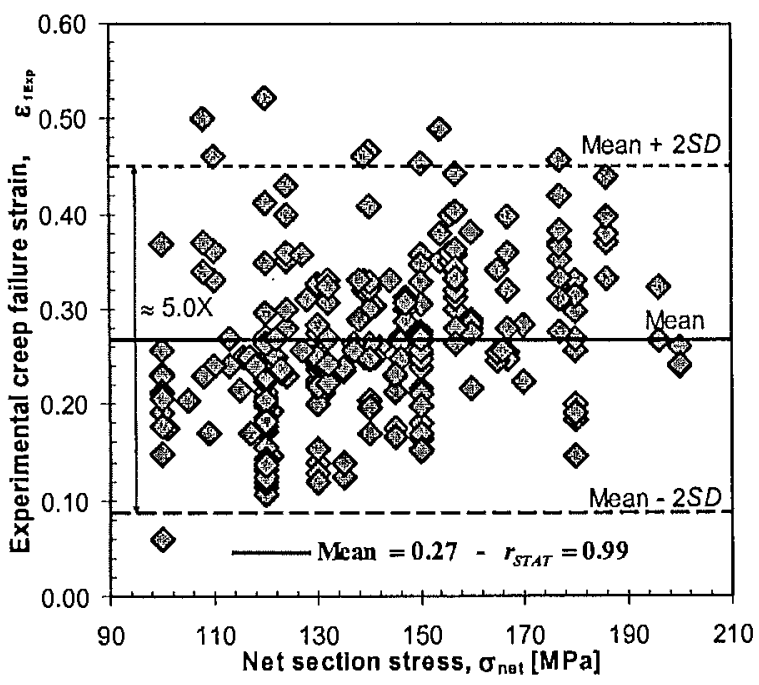

FIG. $8-\varepsilon_{f}$ dependence on $\sigma_{\text {net }}$ for all P91 casts at $600^{\circ} \mathrm{C}$ assuming normal distribution.

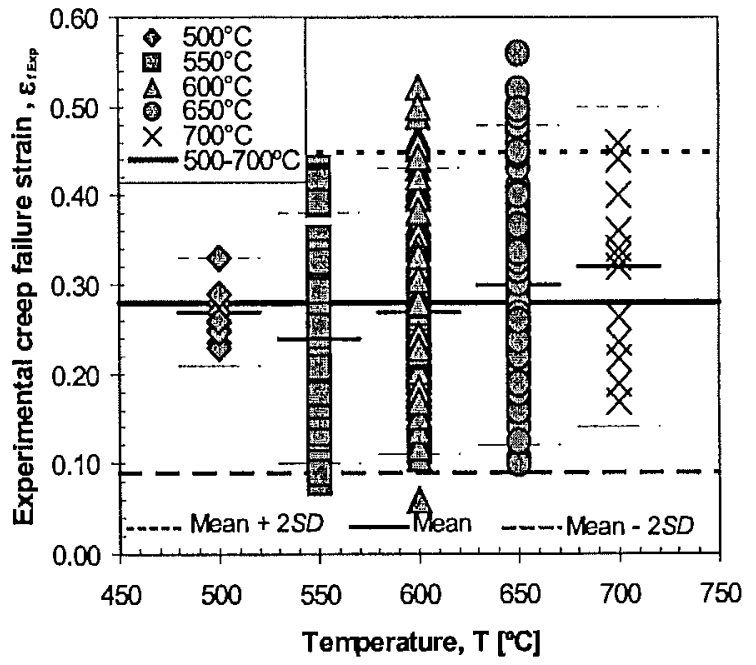

FIG. 9-Effect of temperature on creep failure strain for all casts of P91 steel.
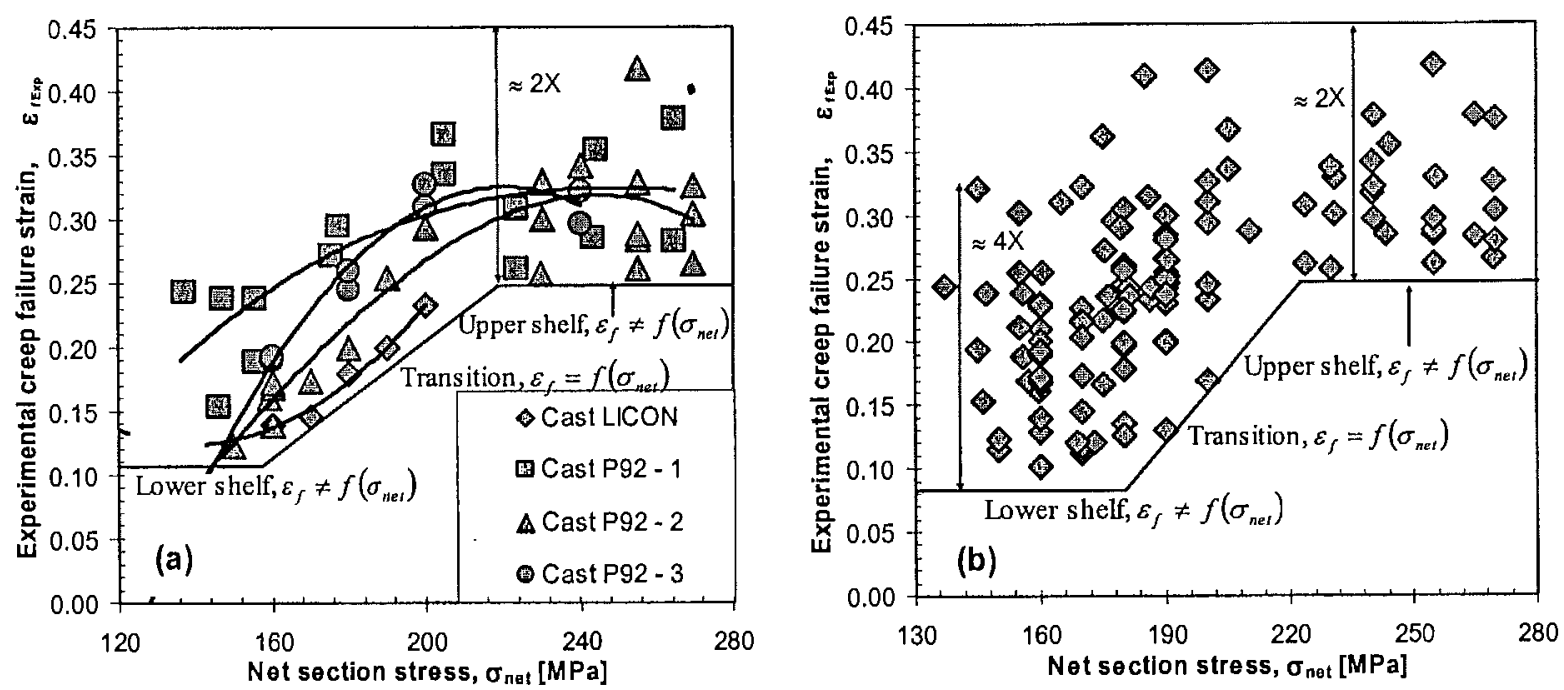

FIG. $10-$ Effect of $\varepsilon_{f}$ on $\sigma_{\text {net }}$ for (a) specific casts and (b) all casts of P92 steel at $600^{\circ} \mathrm{C}$. 


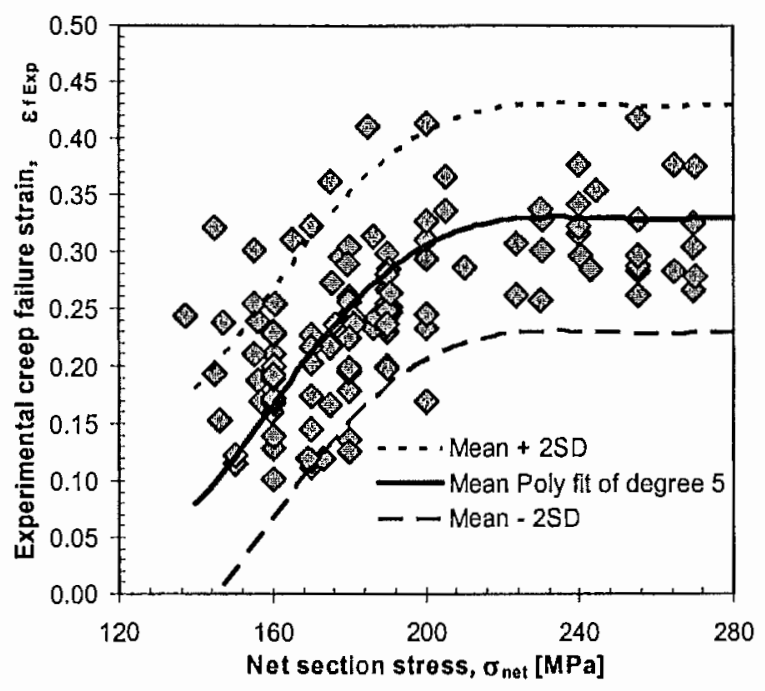

FIG. 11- Fit of polynomial of degree five to all creep ductility data on $P 92$ steel at $600^{\circ} \mathrm{C}$.

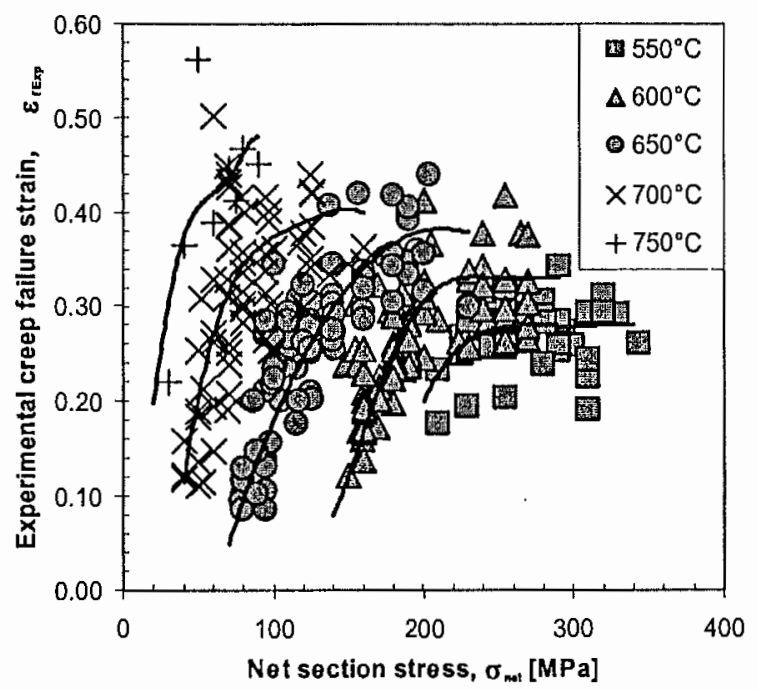

FIG. 12-Effect of temperature on creep failure strain for all tests on P92 steel.

\section{Creep Crack Growth Results}

The results of statistical analysis that have been carried out on the experimental creep crack growth data are given in Table 6 and in Fig. 13. These results will be used in the prediction of creep crack growth section. Also included in Table 6 are the uniaxial material properties obtained on individual batches of the steels used to make the probabilistic calculations based on Monte Carlo simulations (MCS). Figure 13(a) shows that the scatter in CCG rate results for the $316 \mathrm{~L}(\mathrm{~N})$ stainless steel is similar to that of the multicast uniaxial creep data of Fig. 5 although only two batches of the material were tested for the cracking experiments. However, in addition, two sizes of CT specimens were examined. In contrast, in Fig. 13(b) for the more creep brittle $9 \% \mathrm{Cr}$ steel, only one cast of material and one size of the c-shaped specimen were examined and the scatter is found to be much lower: 
WASMER ET AL. ON CREEP CRACK GROWTH 9

TABLE 1-Chemical compositions of $316 L(N), P 91$ and $P 92$ (in weight percent).

\begin{tabular}{cccccccccccccc}
\hline Mat. & $\mathrm{C}$ & $\mathrm{Si}$ & $\mathrm{Mn}$ & $\mathrm{P}$ & $\mathrm{S}$ & $\mathrm{Cr}$ & $\mathrm{Cu}$ & $\mathrm{Mo}$ & $\mathrm{N}$ & $\mathrm{Nb}$ & $\mathrm{Ni}$ & $\mathrm{V}$ & W \\
\hline $316 \mathrm{~L}(\mathrm{~N})$ & 0.040 & 0.310 & 1.830 & 0.036 & 0.020 & 17.30 & 0.030 & 2.460 & 0.070 & - & 11.90 & - & - \\
P91 & 0.106 & 0.320 & 0.470 & 0.016 & 0.001 & 8.930 & 0.110 & 0.940 & 0.065 & 0.067 & 0.300 & 0.210 & - \\
P92 & 0.114 & 0.190 & 0.410 & 0.020 & 0.008 & 9.370 & 0.090 & 0.470 & - & 0.055 & 0.230 & 0.190 & 1.720 \\
\hline
\end{tabular}

TABLE 2-Statistical results of creep analysis for multicasts 316 L(N)-PM steel.

\begin{tabular}{ccccccccc}
\hline Material & $\begin{array}{c}\text { Temp. } \\
\left({ }^{\circ} \mathrm{C}\right)\end{array}$ & No. of tests & $n_{\text {Ave }}$ & $n_{\mathrm{s}}$ & $\nu$ & $\overline{\varepsilon_{f}}$ & $S D \varepsilon_{f}$ & $r_{\text {STAT }}$ for $\varepsilon_{f}$ \\
\hline $316 \mathrm{~L}(\mathrm{~N})$ & 500 & 11 & 11.63 & 16.59 & 8.78 & 0.30 & 0.07 & 0.97 \\
$316 \mathrm{~L}(\mathrm{~N})$ & 550 & 127 & 11.74 & 10.15 & 10.79 & 0.30 & 0.09 & 0.95 \\
$316 \mathrm{~L}(\mathrm{~N})$ & 600 & 124 & 8.96 & 8.76 & 9.38 & 0.41 & 0.15 & 1.00 \\
$316 \mathrm{~L}(\mathrm{~N})$ & 650 & 82 & 7.37 & 8.27 & 7.42 & 0.54 & 0.15 & 0.98 \\
$316 \mathrm{~L}(\mathrm{~N})$ & 700 & 24 & 5.98 & 6.63 & 6.26 & 0.72 & 0.21 & 0.99 \\
$316 \mathrm{~L}(\mathrm{~N})$ & 750 & 15 & 5.78 & 5.78 & 5.47 & 0.80 & 0.16 & 0.90 \\
\hline
\end{tabular}

TABLE 3-Statistical results of creep analysis for multicasts P91-PM steel.

\begin{tabular}{ccccccccc}
\hline Material & Temp. $\left({ }^{\circ} \mathrm{C}\right)$ & No. of tests & $n_{\text {Ave }}$ & $n_{s}$ & $\nu$ & $\overline{\varepsilon_{f}}$ & $S D \varepsilon_{f}$ & $r_{\text {STAT }}$ for $\varepsilon_{f}$ \\
\hline P91 & 500 & 11 & 20.81 & N / A & 21.22 & 0.27 & 0.03 & 0.95 \\
P91 & 550 & 110 & 13.87 & N / A & 12.89 & 0.24 & 0.07 & 0.99 \\
P91 & 600 & 238 & 9.41 & 13.51 & 8.73 & 0.27 & 0.08 & 0.99 \\
P91 & 650 & 145 & 7.98 & N / A & 7.37 & 0.30 & 0.09 & 0.99 \\
P91 & 700 & 13 & 6.71 & N / A & 6.48 & 0.32 & 0.09 & 0.98 \\
P91 & $500-700$ & 668 & N / A & N / A & N/A & 0.27 & 0.09 & 0.99 \\
\hline
\end{tabular}

TABLE 4-Statistical results of creep analysis for multicasts P92-PM steel.

\begin{tabular}{ccccccc}
\hline Material & Temp. $\left({ }^{\circ} \mathrm{C}\right)$ & No. of tests & $n_{\text {Ave }}$ & $n_{\mathrm{s}}$ & $\nu$ & $S D \varepsilon_{f}$ \\
\hline P92 & 550 & 49 & 18.97 & 18.62 & 18.63 & 0.03 \\
P92 & 600 & 125 & 16.15 & 14.88 & 14.76 & 0.06 \\
P92 & 650 & 130 & 11.81 & 11.56 & 10.40 & 0.05 \\
P92 & 700 & 70 & 8.13 & 8.53 & 7.46 & 0.06 \\
P92 & 750 & 8 & 6.74 & 7.35 & 6.23 & 0.08 \\
\hline
\end{tabular}

TABLE 5-Statistical results of multicasts creep failure strain for P92a.

\begin{tabular}{|c|c|c|c|c|c|c|c|c|c|c|c|}
\hline Material & $\begin{array}{l}\text { Temp. } \\
\left({ }^{\circ} \mathrm{C}\right)\end{array}$ & $\begin{array}{c}\text { No. of } \\
\text { tests }\end{array}$ & $\begin{array}{l}\sigma_{\text {net } \mathrm{Max}} \\
(\mathrm{MPa})\end{array}$ & $\begin{array}{l}\sigma_{\text {net Min }} \\
(\mathrm{MPa})\end{array}$ & $\sigma_{\text {net }}^{5}$ & $\sigma_{\text {net }}^{4}$ & $\sigma_{\text {nal }}^{3}$ & $\sigma_{\mathrm{ntet}}^{2}$ & $\sigma_{\text {net }}^{1}$ & $\sigma_{\text {net }}^{0}$ & $\begin{array}{c}r_{\text {STAT }}^{2} \\
\text { for polynomial } \\
\text { expression } \\
\end{array}$ \\
\hline $\mathrm{P92}$ & 550 & 56 & 210 & 350 & $5.57 \cdot 10^{-1.3}$ & $-9.98 \cdot 10^{-11}$ & $6.44 \cdot 10^{-7}$ & $-3.69 \cdot 10^{-4}$ & $8.14 \cdot 10^{-2}$ & -6.15 & 0.65 \\
\hline P92 & 600 & 125 & 135 & 280 & $-2.92 \cdot 10^{-11}$ & $3.30 \cdot 10^{-8}$ & $-1.45 \cdot 10^{-3}$ & $3.10 \cdot 10^{-3}$ & $-3.15 \cdot 10^{-1}$ & 12.30 & 0.76 \\
\hline P92 & 650 & 130 & 70 & 250 & $5.78 \cdot 10^{-12}$ & $-4.51 \cdot 10^{-9}$ & $1.37 \cdot 10^{-6}$ & $-2.18 \cdot 10^{-4}$ & $2.12 \cdot 10^{-2}$ & -0.74 & 0.90 \\
\hline P92 & 700 & 70 & 40 & 160 & $-1.81 \cdot 10^{-11}$ & $4.68 \cdot 10^{-9}$ & $3.92 \cdot 10^{-8}$ & $-2.35 \cdot 10^{-4}$ & $2.62 \cdot 10^{-2}$ & 0.60 & 0.77 \\
\hline P92 & 750 & 8 & 30 & 70 & $-1.28 \cdot 10^{-9}$ & $3.34 \cdot 10^{-7}$ & $-309 \cdot 10^{-5}$ & $-1.13 \cdot 10^{-3}$ & $6.57 \cdot 10^{-3}$ & 0.07 & 0.65 \\
\hline
\end{tabular}

TABLE 6-Experimental creep crack growth results and uniaxial data used in MCS.

\begin{tabular}{|c|c|c|c|c|c|c|c|c|c|c|c|c|c|c|c|c|c|}
\hline \multirow[b]{2}{*}{ Material $\left.\right|^{a}$} & \multirow[b]{2}{*}{ Batch } & \multirow[b]{2}{*}{$\begin{array}{l}\text { Temp. } \\
\left({ }^{\circ} \mathrm{C}\right)\end{array}$} & \multicolumn{7}{|c|}{ Experimental creep crack growth results } & \multicolumn{8}{|c|}{ Experimental uniaxial creep results } \\
\hline & & & Spec. & $\begin{array}{l}\text { No. of } \\
\text { tests/ } \\
\text { points }\end{array}$ & $\log (D)$ & $\phi$ & $\begin{array}{c}S D \\
\dot{a} \\
\end{array}$ & $\begin{array}{l}\text { Ratio } \\
\pm 2 S D\end{array}$ & $r_{\text {STAI }}^{2}$ & $\begin{array}{c}\text { No. of } \\
\text { tests }\end{array}$ & $\operatorname{Ratio}_{D}$ & $A_{\text {ave }}$ & $n_{\text {aye }}$ & $\overline{E_{r}}$ & $S D \varepsilon_{r}$ & $\begin{array}{l}\text { Ratio } \\
\pm 2 S D\end{array}$ & $\begin{array}{l}r_{\mathrm{STAT}} \\
\text { for } \varepsilon_{f} \\
\end{array}$ \\
\hline $316 \mathrm{~L}(\mathrm{~N})$ & HIDA & 650 & CT & $7 / 89$ & 0.44 & 0.83 & 0.30 & 16.0 & 0.95 & 5 & 2.74 & $1.9 \mathrm{E}-22$ & 8.35 & 0.54 & 0.15 & 3.5 & 0.99 \\
\hline P91 & LICON & 600 & C-shape & $6 / 109$ & 0.69 & 0.70 & 0.16 & 4.4 & 0.93 & 8 & 1.33 & $1.2 \mathrm{E}-32$ & 13.30 & 0.27 & 0.09 & 5.0 & 0.99 \\
\hline P92 & $\mathrm{LICON}$ & 625 & C-shape & $2 / 47$ & 0.92 & 0.75 & 0.11 & 2.8 & 0.98 & 6 & 1.49 & $7.4 \mathrm{E}-34$ & 13.59 & 0.18 & 0.05 & 3.5 & 0.99 \\
\hline
\end{tabular}

${ }^{\mathrm{a} D a t a s e t}$ for $316 \mathrm{~L}(\mathrm{~N})$-PM-CT specimens comes from the HIDA project. In contrast, the dataset for P91 and P92-C-shaped specimens comes from the LICON project. 

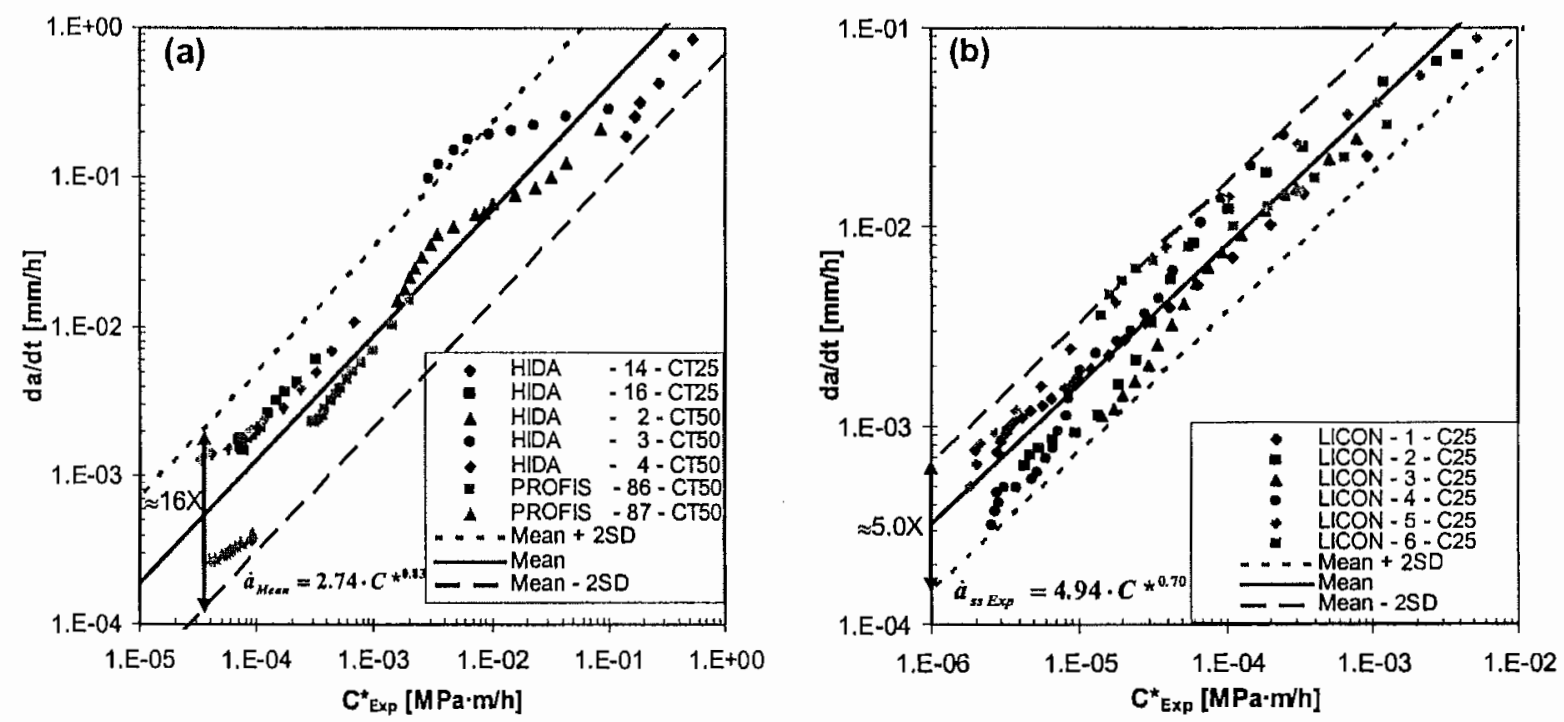

FIG. 13 - Experimental creep crack growth results for (a) $316 L(N)-P M-C T$ at $650^{\circ} \mathrm{C}$ and (b) P91-PM$\mathrm{C} 25$ at $600^{\circ} \mathrm{C}$.

\section{Prediction of Creep Crack Growth Data}

Monte Carlo simulation (MCS) methods $[1,26,27]$ have been applied to predict the scatter in the crack growth data from the uniaxial creep properties. Two procedures were employed. In one instance, values of $C^{*}$ within the experimental range were chosen at random and estimates of crack growth rate obtained from

$$
\dot{a}=\frac{D}{\left(1+\frac{e_{\varepsilon_{f}}}{\overline{\varepsilon_{f}}}\right)} C^{* \phi}
$$

where the values of $D$ and $\phi$ were taken from Table 6 to correspond with the specific batches of the steels used in the CCG tests. Equation 9 allows the scatter in the creep failure strain data to be compared with the one observed in the creep crack growth tests. In fact, in this equation, $\overline{\varepsilon_{f}}$ is the mean creep failure strain and $e_{\varepsilon_{f}}$ is the error in this strain that is chosen randomly in the Monte Carlo simulation. The values of $e_{\varepsilon_{f}}$ correspond with the distribution in experimental failure strains obtained from the statistical analysis performed on the single batch uniaxial data shown in Table 6 . The predictions for each material are shown in Figs. 14(a) and 15. Almost identical bounds for the $9 \% \mathrm{Cr}$ steels are obtained to those measured experimentally. In contrast to $316 \mathrm{~L}(\mathrm{~N})$, the predicted bounds is more or less four times less than the experimental one. The increased CCG experimental scatter for $316 \mathrm{~L}(\mathrm{~N})$ stainless steel is attributed to three main factors. First, the highly ductile cracking behavior in this steel (see Fig. 4) at $650^{\circ} \mathrm{C}$ produces a larger scatter of a factor of 16 between $\pm 2 S D$ [see Fig. 13(a)] compared to P91 [Fig. 13(b)] which gives a scatter * factor of 5 . The first reason is the exceptionally large scatter observed between $\pm 2 S D$ [factor 16 in Figs. $13(a)$ and $15(a)$ ] for the creep crack growth data [1]. Second, in the present dataset for the $316 \mathrm{~L}(\mathrm{~N})$ stainless steel, two material batches and two CT specimen sizes were used (CT with the width $W=25$ and 50). This may necessitate the use of two values of $\varepsilon_{f}^{*}$ to allow for the effect of different constraints in the two sizes of specimens. Finally, for a material with creep ductility $<50 \%$, the ratio between $\pm 2 S D$ will always be less than four assuming a standard deviation of 0.15 . This comes from the fact that the ratio is calculated from

$$
\text { Ratio } \pm 2 S D=\frac{\overline{\varepsilon_{f}}+2 S D}{\overline{\varepsilon_{f}}-2 S D}
$$

It is obvious that assuming a constant standard deviation, the ratio between $\pm 2 S D$ is only dependent on $\overline{\varepsilon_{f}}$. Higher is this value, smaller is the ratio $\pm 2 S D$. It can be concluded from these two statements that the creep failure ductility must not be used to predict the scatter in creep crack growth data when $\overline{\varepsilon_{f}}>0.5$ and SD $\dot{a}>10$. Finally, it is apparent, in all cases, that the cracking data can be correlated by an expression of the form of Eq 2. The average values obtained for $D$ and $\phi$, together with the standard deviations produced in crack propagation rate, are listed in Table 6. Bounds for the two standard deviations spread in the 

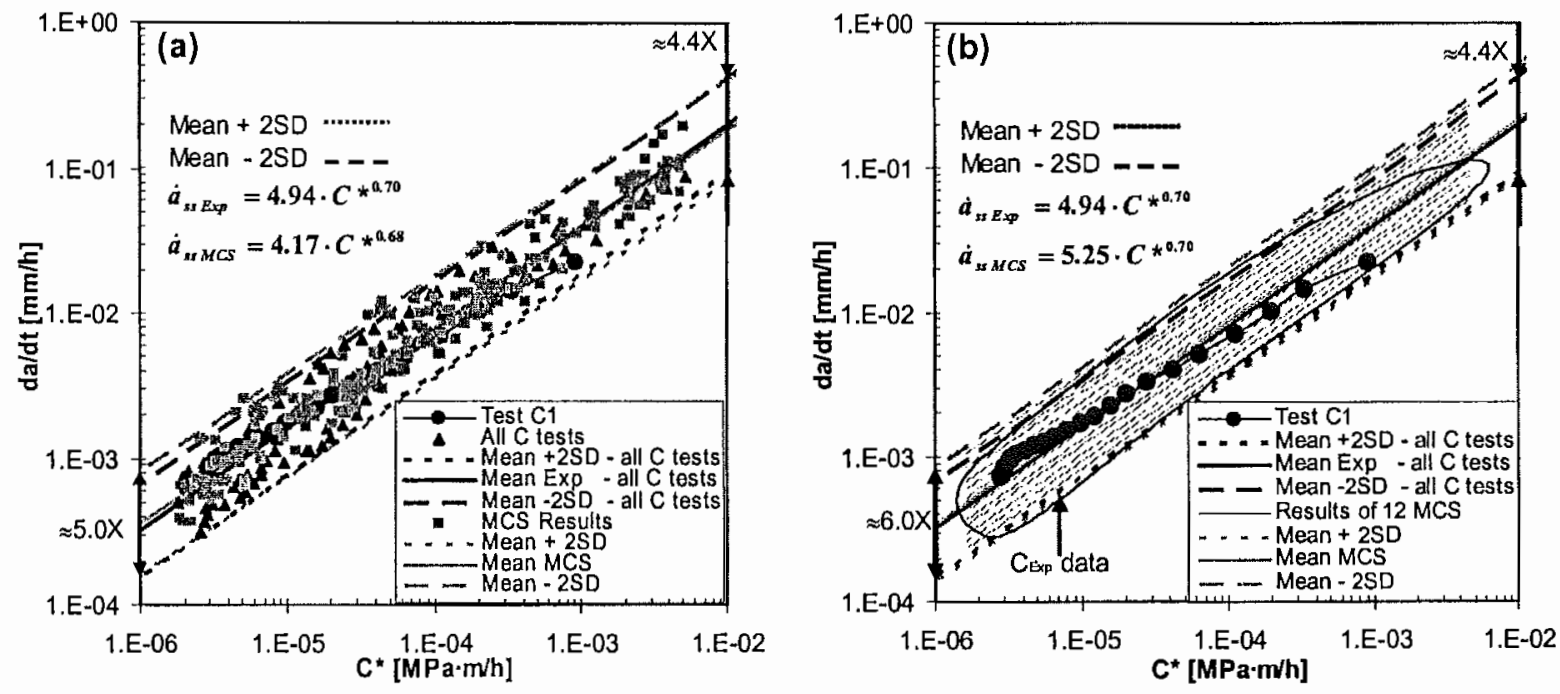

FIG. 14-Comparison between experimental and predicted scatter in crack growth data for P9I steel at $600^{\circ} \mathrm{C}$ when (a) $C^{*}$ is determined experimentally and (b) $C^{*}$ is calculated from reference stress methods.
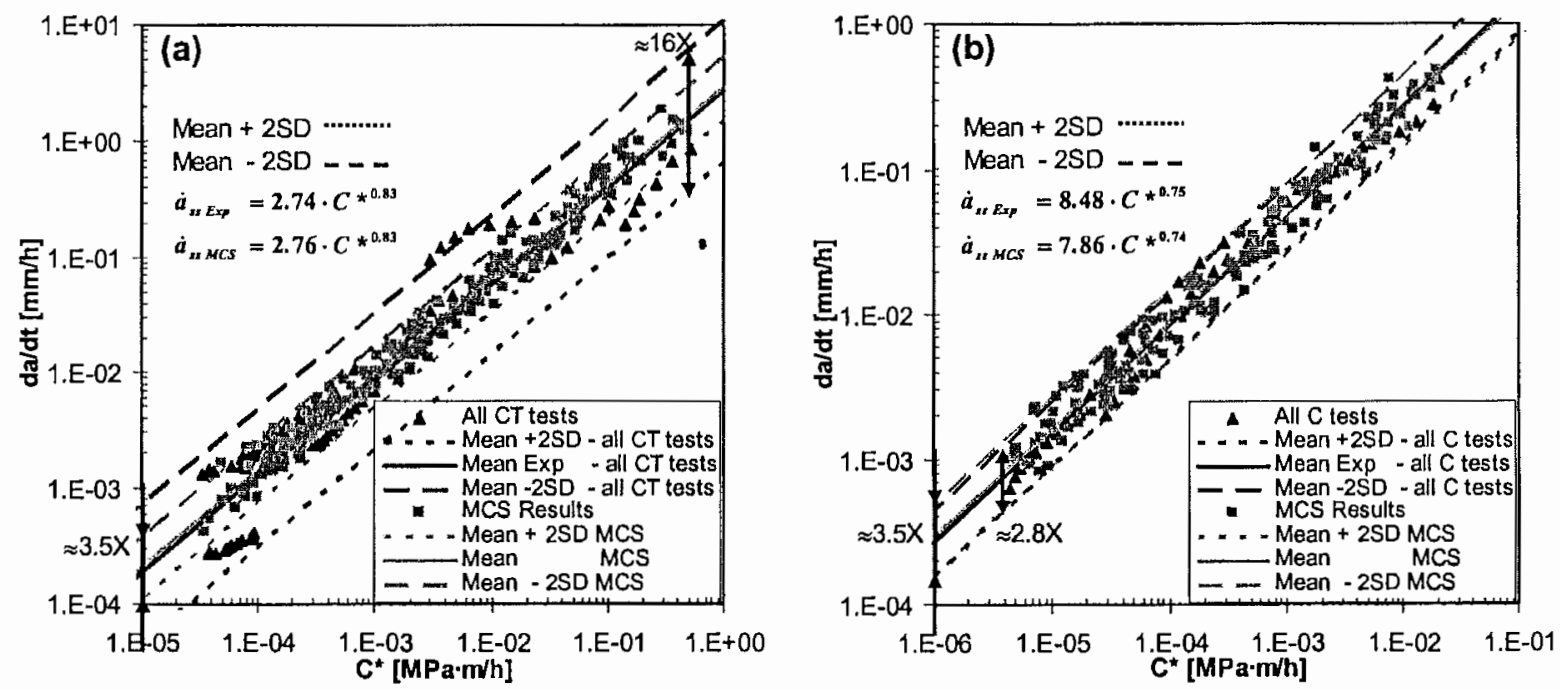

FIG. 15-Comparison between experimental and predicted scatter in creep crack growth data and $C^{*}$ determined experimentally for (a) $316 \mathrm{~L}(\mathrm{~N})$ steel at $650^{\circ} \mathrm{C}$ and (b) P92 steel at $625^{\circ} \mathrm{C}$.

experimental data are included in the figures. It is apparent, in all cases, that the cracking data can be correlated by an expression of the form of Eq 2 .

Comparisons were also made using the alternative procedure for predicting scatter in crack growth data. In this instance, $C^{*}$ was determined by reference stress methods $[9,10]$ from

$$
C^{*}=\sigma_{\text {ref }} \cdot \dot{\varepsilon}_{\text {ref }} \cdot\left(\frac{K}{\sigma_{\text {ref }}}\right)^{2}
$$

where $K$ is stress intensity factor and $\dot{\varepsilon}_{\text {ref }}$ is the creep strain rate at reference stress $\sigma_{\text {ref }}$. It has already been shown that creep crack growth predictions are sensitive to the reference stress formula and creep strain rates [1] and $[28,29]$. Consequently, the Monte Carlo simulation procedure was employed as previously except in this case $C^{*}$ was calculated from $\mathrm{Eq} 11$. To avoid the influence of the reference stress and materials properties, these parameters were selected to give the best approximation of the experimental $C^{*}$, $C_{\text {Exp }}^{*}$. For the test C1-PM, the best $\sigma_{\text {Ief }}$ is taken from plane strain-Von Mises (Pع-VM). The mean average creep rate, obtained from rupture data, was used in the calculations to determine $\dot{\varepsilon}_{\text {ref }}$, without taking into account its scatter to only investigate the influence of variation in $\varepsilon_{f}$, to allow approximately for all stages of creep. The material properties employed are based on the average strain rate and are given in Table 6 . 
The results are presented in Fig. 14(b). Again a virtually identical spread in the data is predicted to that measured experimentally. It is evident, whichever method of determining $C^{*}$ is adopted, that similar overall predictions of experimental scatter can be replicated by the MCS method. The analysis demonstrates that experimental scatter in creep crack growth data can be predicted from the scatter in uniaxial creep rupture strain when $\overline{\varepsilon_{f}}>0.5$ and $S D \dot{a}>10$.

\section{Conclusions}

The scatter in uniaxial creep data on type $316 \mathrm{~L}(\mathrm{~N})$ stainless steel and two $9 \% \mathrm{Cr}$ steels designated $\mathrm{P} 91$ and P92 has been analyzed statistically. It has been found that none of the rupture time $\left(t_{R}\right)$, the creep strain rate $(\dot{\varepsilon})$, and the net section stress $\left(\sigma_{\text {net }}\right)$, has a better relationship with the $\varepsilon_{f}$. Hence, none of these parameters characterizes better than the other the creep ductility's behavior: Additionally, the results from different batches of one material can be treated individually but that a clear trend can be established only when they are treated as one large dataset with the variability in creep ductility exhibiting a normal distribution with a bigger standard deviation to that of an individual batch of material. It has also been established that the creep failure strains of the $316 \mathrm{~L}(\mathrm{~N})$ stainless steel and the P91 steel are independent of stress whereas, for the P92 steel, creep failure strain increases with stress. In addition it has been shown for all the steels that the standard deviation in creep ductility tends to increase with an increase in temperature. However, this does not necessarily implie an increase in scatter since the ratio between $\pm 2 S D$ is strongly dependent on $\overline{\varepsilon_{f}}$. A probabilistic approach has been adopted, using Monte Carlo simulation methods, to predict the expected scatter in creep crack growth data from that experienced by the creep failure strain. It is demonstrated for each material that close agreement is achicved, in most instances, with the experimental scatter observed in crack growth tests for conditions where $\overline{\varepsilon_{f}}>0.5$ and SD $\dot{a}>10$. The results of this investigation indicate, that when only sparse creep crack growth information is available, the scatter in the data can be predicted from the scatter in creep ductility irrespective of whether $C^{*}$ is determined experimentally or by reference stress methods. Due to the increase in scatter observed in creep failure strain with an increase in temperature, it is anticipated that, for materials where $\overline{\varepsilon_{f}}$ is insensitive to the temperature, as for P91, the spread in creep crack growth data should also get larger as the test temperature rises.

\section{Acknowledgments}

The authors would like to acknowledge the provision of data from the European Brite/Euram "HIDA" (1996-2000), "LICON" (1997-2001), and CRETE (2001-2004) project partners.

\section{References}

[1] Wasmer, K., "Prediction of Creep Crack Growth for a Range of Steels," Ph.D. Thesis, Mechanical Engineering Department, Imperial College, London, 2003.

[2] Commissariatà l'Energie Atomique. A16, "Guide for Defect Assessment and Leak Before Break Analysis," 3rd ed., Saclay, CEA, 1995.

[3] Commissariatà l'Energie Atomique. A16, "Guide for Defect Assessment and Leak Before Break Analysis," 4th ed., Saclay, CEA, 2002.

[4] R5-British Energy, "Defect Assessment Code of Practice for High Temperature Metallic Components," British Energy Generation Ltd., 1999.

[5] BS 7910, "Guide on Methods for Assessing the Acceptability of Flaws in Fusion Welded Structures," London, BSI, 2000.

[6] Nikbin, K. M., Webster, G. A., and Turner, C. E., Relevance of Non-Linear Fracture Mechanics to Creep Cracking, Cracks and Fracture, ASTM STP 601, Pittsburgh, pp. 47-62, 1976.

[7] Webster G. A. and Ainsworth R. A., High Temperature Components Life Assessment. Chapman \& Hall, London, 1993.

[8] ASTM Standard E 1457-00, "Standard Test Method for Measurement of Creep Crack Growth Rates in Metals," Annual Book of ASTM Standards, Vol. 3, No. 1, ASTM International, West Consho- 
hocken, 936-950, (2001).

[9] Ainsworth, R. A., "Some Observations on Creep Crack Growth," Int. J. Fract., 20, 147-159 (1982).

[10] Ainsworth, R. A., "The Assessment of Defects in Structure of Strain Hardening Materials," Eng. Fract. Mech., 19, 633-642 (1984).

[11] Nikbin, K. M., Smith, D. J., and Webster, G. A. "Influence of Creep Ductility and State of Stress on Creep Crack Growth," Advances in Life Prediction Methods at Elevated Temperatures, ASME International Conference, New York edited by D. A. Woodford and J. R. Whitehead 1983, 249-258 (1983).

[12] Nikbin, K. M., Smith, D. J., and Webster, G. A. "Prediction of Creep Crack Growth from Uniaxial Creep Data," Proc. R. Soc. London, Ser. A 396, 183-197 (1984).

[13] Lehmann, D., "Final Report: Evaluation of the Stress to Rupture and Creep Properties of Type 316 L(N) Steel for Design Use," European Commission: Nuclear Science and Technology, EUR-16168, 1995.

[14] Hyde, T. H., "Creep of 316 Stainless Steel at $500^{\circ}$ and $600^{\circ} \mathrm{C}$ and the Effects of Short Duration Overloads on Creep at $550^{\circ} \mathrm{C}, "$ Mater. High. Temp., 14,(1), 27-35 (1997).

[15] NRIM Creep Data Sheet No. 43, "Data Sheets on the Elevated Temperature Properties of 9Cr-1Mo$\mathrm{V}-\mathrm{Nb}$ Steel Plates for Boilers and Pressure Vessels (ASME SA-387/SA-387M Grade 91), 1996.

[16] Bendick, W., "Damage Assessment on P91 Specimens from Uniaxial Creep Tests: Final. Report," Mannesmann Forschunginstitut, LICON/MFI 016/TR07, 1999.

[17] Prunier, V., Gampe, U., Nikbin, K. M., and Shibli, A., "HIDA Activity on P91 Steel," Mater: High. Temp., 15, 35-42 (1998).

[18] Schuster, F. A. and Hanus, R., "Foundry Experience in Large Turbine Casings and Valve Bodies made of Steel Castings P91 and G-X12 CrMoWVNbN 10 11," Paper presented at the Creep and Fatigue, London, 1999, 11-22.

[19] Hald, J., "Creep Strength and Ductility of 9 to 12\% Chromium Steels," Mater. High. Temp. 21(1), $41-46$ (2004).

[20] Ricci, N. and Bontempi, P., "Metallographic Examination of P91, P92 and E911 Specimens Tested in the Frame of the LICON Task 3," Centro Elettrotecnico Sperimentale Italiano, LICON/CESI011/ PR08, 2000.

[21] Taylor, N., Lucon, E., Bicego, V., and Bontempi, P., "Crack Stability Assessment of Advanced 9CR Steels in Boilers Components," Paper presented at the Advanced Steam Plant, London, 1997, pp. 201-210.

[22] Verelst, L., "Creep Test Results of Accelerated Damage Enhancement (ADE) Testing," LABORELEC, LICON/LE 007/TR03, 1998.

[23] Holdsworth, S. R. and Davies, R. B., "A Recent Advance in the Assessment of Creep Rupture Data," Nucl. Eng. Des., 190,(3), 287-296 (1999).

[24] NRIM Creep Data Sheet No. 48 Data Sheets on the Elevated-Temperature Properties of 9Cr-0.5Mo1.8W-V-Nb Steel Pipe for High Temperature Service (ASME SA-335/SA-335M Grade P92), 2002.

[25] ASTM Standard E 139-00, "Standard Test Method for Conducting Creep, Creep-Rupture and StressRupture Tests of Metallic Materials," Annual Book of ASTM Standards, Vol. 3(1), West Conshohacken, PA, pp. 270-281, 2001.

[26] Nikbin, K. M., Yatomi, M., Wasmer, K., and Webster, G. A., "Probabilistic Analysis of Creep Crack Initiation and Growth in Pipes Components," Int. J. Pressure Vessels Piping, 80(7-8), 585-595 (2003).

[27] Wasmer, K., Nikbin, K. M., and Webster, G. A., "Sensitivity of Creep Crack Initiation and Growth in Plates to Material Properties Variations," J. Am. Inst. Electr. Eng., 2(1) (2005).

[28] Wasmer, K., Nikbin, K. M., and Webster, G. A. "A Sensitivity Study of Creep Crack Growth in Pipes," PVP Vol. 438, New and Emerging Computational Methods: Applications to Fracture, Damage and Reliability, ASME, New York, 2002, pp. 17-24.

[29] Wasmer, K., Nikbin, K. M., and Webster, G. A., "Creep Crack Initiation and Growth in Thick Section Steel Pipes under Internal Pressure," Int. J. Pressure Vessels Piping, 80(7-8), 489-498 (2003). 